\title{
Laboratory Medicine Handoff Gaps Experienced by Primary Care Practices: A Report from the Shared Networks of Collaborative Ambulatory Practices and Partners (SNOCAP)
}

\author{
David R. West, PhD, Katherine A. James, MSCE, PhD, Douglas H. Fernald, MA, \\ Claire Zelie, MPH, Maxwell L. Smith, MD, and Stephen S. Raab, MD
}

Background: The majority of errors in laboratory medicine testing are thought to occur in the pre- and postanalytic testing phases, and a large proportion of these errors are secondary to failed handoffs. Because most laboratory tests originate in ambulatory primary care, understanding the gaps in handoff processes within and between laboratories and practices is imperative for patient safety. Therefore, the purpose of this study was to understand, based on information from primary care practice personnel, the perceived gaps in laboratory processes as a precursor to initiating process improvement activities.

Design: A survey was used to assess perceptions of clinicians, staff, and management personnel of gaps in handoffs between primary care practices and laboratories working in 21 Colorado primary care practices. Data were analyzed to determine statistically significant associations between categorical variables. In addition, qualitative analysis of responses to open-ended survey questions was conducted.

Results: Primary care practices consistently reported challenges and a desire/need to improve their efforts to systematically track laboratory test status, confirm receipt of laboratory results, and report results to patients. Automated tracking systems existed in roughly $61 \%$ of practices, and all but one of those had electronic health record-based tracking systems in place. One fourth of these electronic health record-enabled practices expressed sufficient mistrust in these systems to warrant the concurrent operation of an article-based tracking system as backup. Practices also reported 12 different procedures used to notify patients of test results, varying by test result type.

Conclusion: The results highlight the lack of standardization and definition of roles in handoffs in primary care laboratory practices for test ordering, monitoring, and receiving and reporting test results. Results also identify high-priority gaps in processes and the perceptions by practice personnel that practice improvement in these areas is needed. Commonalities in these areas warrant the development and support of tools for use in primary care settings. (J Am Board Fam Med 2014;27:796-803.)

Keywords: Laboratories, Practice-based Research, Primary Health Care

This article was externally peer reviewed.

Submitted 15 January 2014; revised 19 August 2014; accepted 25 August 2014.

From the Department of Family Medicine, University of Colorado Denver, Aurora (DRW, KAJ, DHF, CZ); the Department of Laboratory Pathology, Mayo Clinic, Scottsdale, AZ (MLS); the Department of Pathology, University of Washington, Seattle (SSR); and the Department of Pathology, Memorial University/Eastern Health, St John's, Newfoundland, Canada (SSR).

Funding: The research described in this article was funded by the Centers for Disease Control and Prevention, Division of Laboratory Programs, Standards, and Services, via cooperative agreement no. U47CI000832.

Conflict of interest: none declared.

Both the Institute of Medicine (IOM) and the Joint Commission have identified failed patient handoffs as a cause of medical errors leading to a significant

Disclaimer: The opinions expressed by authors do not necessarily reflect the opinions of the U.S. Department of Health and Human Services, the Public Health Service, the Centers for Disease Control and Prevention, or the authors' affiliated institutions. Use of trade names is for identification only and does not imply endorsement by any of the groups named above.

Corresponding author: David R. West, PhD, Department of Family Medicine, University of Colorado School of Medicine, 12477 E. 19th Ave, Bldg 406 M/S F44, Aurora, CO 80045 (E-mail: David.West@ucdenver.edu). 
number of sentinel events. ${ }^{1,2}$ Laboratory medicine in primary care is no exception to this; it is frequently characterized by a constellation of multiple-step processes with critical cross-domain handoffs occurring among patients, clinical care teams, and laboratories. ${ }^{3}$

Studies examining the frequency and causes of laboratory errors in primary care indicate that ambulatory care practice characteristics affect error detection and frequency. ${ }^{4}$ For example, practices lacking a specific system to manage laboratory test orders are twice as likely to report errors as practices with a system. ${ }^{5}$ As many as half of physician-reported errors have been related to the laboratory testing process. ${ }^{6-8}$ Studies report that the consequences of many laboratory medicine handoff errors include delayed care, increased costs, and patient pain and suffering.,

In 2010, the Centers for Disease Control and Prevention initially funded the University of Colorado Health Outcomes Program (Aurora, CO) to design quality improvement initiatives that would bridge current gaps in primary care-laboratory medicine handoffs. As the first step, practices participating in the Shared Networks of Collaborative Ambulatory Practices and Partners (SNOCAP) practice-based research network, researchers, and laboratory personnel (pathologists) used qualitative and quantitative practice survey data to identify perceived gaps in laboratory testing processes by key role within the primary care practice and to identify specific laboratory testing processes as targets for in-depth study before initiating process improvement. The findings reported here provide both laboratories and primary care practices with a greater understanding of the management of laboratory tests, including handoff failures, with a goal of informing efforts to transcend cross-domain barriers and foster partnerships in the solutions for improving laboratory medicine care.

\section{Methods}

A survey method was used to assess perceptions regarding gaps in primary care before and after analytic laboratory testing processes. The questionnaire for the survey was designed to discretely measure staff and provider perceptions about how practices manage laboratory test ordering and tracking, patient notification, and patient follow-up. Laboratory tracking is an information-gathering and documentation process associated with managing handoffs. In this study, handoffs included transmission of clinicians' orders to other personnel in the practice, test requests from practices to laboratories, transmission of laboratory results from laboratories to clinics, and the ultimate communication of these results to patients. This study was reviewed for human subjects protections and was approved by the Colorado Multiple Institutional Review Board.

\section{Practice Recruitment}

We recruited ambulatory care practices from the SNOCAP practice based research network that are affiliated with the University of Colorado Department of Family Medicine (Aurora, CO). Practices within SNOCAP comprise predominantly family medicine physicians, with some pediatric and internal medicine practices (one of each were included in the survey). A recruitment E-mail with information on the study's aims was sent to practice managers in March 2011. Practices that did not respond received a follow-up E-mail 4 to 6 weeks after the initial invitation. A payment of $\$ 250$ was offered to each practice for participation. A total of 43 practices were contacted to consider participation in this survey.

Using an approach like that described by Dillman, ${ }^{10}$ questionnaires were distributed via mail to the participating practices in rural, urban, and suburban settings during the recruitment period (March to June 2011). Using the expectations of $60 \%$ to $80 \%$ return rates from homogeneous response groups, as published by Dillman, ${ }^{10}$ we established a goal of a 70\% internal response rate from each practice organization for inclusion of each practice's results in the analysis. All practices received 2 reminder E-mails to complete and return the questionnaires.

\section{Questionnaire Design}

We developed the survey questionnaire subsequent to conducting a review of the literature about previously developed tools and research in this area. ${ }^{4}$ The questionnaire was modeled after an instrument developed by the American Academy of Family Physicians National Research Network (Test Processing Survey Questionnaire). ${ }^{5}$ All questionnaires were produced using the Snap Survey software program (Snap Surveys Ltd, Bristol, UK) that allows completed surveys to be scanned for efficient data entry, review, and analysis.

A general practice questionnaire was administered to collect practice demographics and infor- 
mation about general processes, along with instruments including questions tailored specifically for personnel in 3 practice role categories: practice staff, clinicians, and practice managers. Staff included nurses, medical assistants, medical records, clerical personnel, front desk staff, and practicebased phlebotomists. Clinicians included physicians, nurse practitioners, physician assistants, and other independent clinicians (eg, pharmacists and psychologists). Practice or office managers included individuals who were generally nonphysician administrators responsible for practice coordination and management.

The tailored questionnaires were quite similar to one another, examining perceptions of handoffs before and after analytic processes and transitions within these processes, as well as the perceptions of roles and responsibilities of the survey respondent and those of personnel in the other role categories. In each case, we sought to gather information about practice policies regarding laboratory test processes, the nature of the processes themselves (including documentation and perceived roles of clinic personnel in carrying out the processes), and problems that were associated with these processes. The questionnaire focused exclusively on routine diagnostic tests such as blood, urine, and stool tests; it did not include imaging, body function, biopsy, endoscopy, or special studies. Table 1 summarizes the processes that were explicitly explored with the questionnaires.

The questionnaire posed specific questions to gather data concerning respondents' perceptions of the quality of processes in place within their practices and those aspects of laboratory testing processes that could be changed or improved. Most questions had structured response categories composed of binary (yes or no) responses, 4- or 5-point Likert scale responses, and nominal response options. In addition, open-ended questions were included to allow respondents to discuss the per- ceived gaps in their processes and to offer suggestions for improvement. The questionnaire was pilot tested with members of the practicing faculty at the Department of Family Medicine at the University of Colorado (Aurora, CO), whose suggestions for clarity and ease of use were incorporated into the final questionnaire (Appendix 1, available upon request from the authors).

\section{Statistical Analysis}

Data were analyzed using the SAS statistical software package, version 9.2 (SAS Institute, Inc., Cary, NC). Survey data initially were analyzed descriptively, and exploratory analysis was performed to identify the variables of highest interest. Analyses of contingency tables ( $\chi^{2}$ statistics), complemented by analyses of standardized residuals, determined statistically significant associations between categorical variables. Statistical significance was assumed at a conservative level of $P \leq .01$.

\section{Qualitative Analysis}

For open-ended survey responses, a content analysis ${ }^{11}$ was conducted using a process in which at least 2 investigators independently evaluated the content of each question to identify the general ideas/themes that were expressed. Each investigator numerically coded each individual idea/theme, and the codes and general trends were assessed across statements. Once complete, the investigators compared their assessments, and differences were resolved by continued discussion until consensus was reached.

\section{Results}

Initially, 43 Colorado-based practices were contacted for this study, and 21 agreed to participate. From among the cohort of 21 practices we received 384 completed questionnaires. This resulted in a

Table 1. Laboratory Processes Explored

\begin{tabular}{l}
\hline Process \\
$\begin{array}{l}\text { The clinician's decision process about which test(s) to order and the transmission of that information } \\
\text { to personnel responsible for performing the test or obtaining the specimen }\end{array}$ \\
$\begin{array}{l}\text { The clinic's internal monitoring and reconciliation processes for the expected transmission of results } \\
\text { of tests ordered from laboratories }\end{array}$ \\
$\begin{array}{l}\text { Thest result notification } \\
\text { transmitted to the patient }\end{array}$ \\
$\begin{array}{c}\text { The processes by which abnormal test results or results needing action by the patient are tracked } \\
\text { until that action is taken or refused by the patient }\end{array}$
\end{tabular}


final analytic cohort of responses from 135 clinicians, 192 staff personnel, 18 practice managers (responses from 2 practice managers were received from within the same practice), and 39 individuals whose role in the practice was unclear. Table 2 summarizes practice characteristics (of those included) that were representative of the practice membership of SNOCAP. We noted that 17 of the 21 practices had an internal completion rate of at least $70 \%$ among physicians, staff, and practice managers $(n=345)$. With regard to the roles and activities of clinicians versus staff in performing laboratory processes, analysis of the reported perceptions of individuals within practices were limited to these responses (as displayed in Tables 3 and 4).

\section{Test-Ordering Processes}

Clinicians identified the electronic health record (EHR) (52\%) and clinical flow sheets and guidelines $(50 \%)$ as primary aids for laboratory test ordering. The most common methods of transmitting test orders to laboratories were hard copy requisition forms (40\%) and EHR-based computerized provider order entry (CPOE) $(38 \%)$.
In general, respondents characterized their test ordering processes as functioning least adequately.

\section{Test-Tracking Processes}

While more than half of practices (61\%) reported the use of an automated system to track laboratory tests once they are ordered, $37 \%$ of clinicians and $18 \%$ of staff reported that their practice had "no system" for tracking or reconciling laboratory test orders and results. Practices with less than a $25 \%$ Medicaid payer mix and those in urban settings were less likely to have any tracking system in place; if they did, they were more likely to report their tracking to be "poor" $(P=.001)$. Test tracking was the specific area that clinician respondents were most interested in improving (57\%). Numerous respondents qualitatively described their concern about the lack of tracking systems or the failure of these systems, including one fourth of practices with EHR tracking systems that reported the concurrent use of error-prone and labor-intensive Article-based systems as backups.

Table 2. Characteristics of Participating Primary Care Practices $(n=21)$

\begin{tabular}{|c|c|c|c|}
\hline \multicolumn{2}{|l|}{ Characteristic } & \multicolumn{2}{|l|}{ Practices, n (\%) } \\
\hline \multicolumn{2}{|l|}{ Electronic health record utilization } & \multicolumn{2}{|l|}{$17(81)$} \\
\hline \multicolumn{2}{|l|}{ Disease registry utilization } & \multicolumn{2}{|l|}{$20(95)$} \\
\hline \multicolumn{2}{|l|}{ Rural location } & \multicolumn{2}{|l|}{$9(43)$} \\
\hline \multicolumn{4}{|l|}{ Practice patient volume } \\
\hline \multicolumn{2}{|l|}{ Small ( $<60$ patient visits/day) } & \multicolumn{2}{|l|}{$7(33)$} \\
\hline \multicolumn{2}{|l|}{ Medium (60-100 patient visits/day) } & \multicolumn{2}{|l|}{$8(38)$} \\
\hline \multicolumn{2}{|l|}{ Large ( $>100$ patient visits/day) } & \multicolumn{2}{|l|}{$6(29)$} \\
\hline \multicolumn{4}{|l|}{ Medicaid and Medicare population/payer mix } \\
\hline \multicolumn{2}{|l|}{$>25 \%$ of patient population insured by Medicaid } & \multicolumn{2}{|l|}{$14(67)$} \\
\hline \multicolumn{2}{|l|}{$>20 \%$ of patient population insured by Medicare } & \multicolumn{2}{|l|}{$7(33)$} \\
\hline \multicolumn{2}{|l|}{ Past participation in formal practice improvement } & \multicolumn{2}{|l|}{$17(81)$} \\
\hline \multicolumn{4}{|l|}{ On-site processes } \\
\hline \multicolumn{2}{|l|}{ Phlebotomy } & \multicolumn{2}{|l|}{$14(67)$} \\
\hline \multicolumn{2}{|c|}{ Preparation of blood samples before transport to the laboratory } & \multicolumn{2}{|l|}{$12(57)$} \\
\hline \multicolumn{2}{|l|}{ Collection of stool samples } & \multicolumn{2}{|l|}{$20(95)$} \\
\hline \multicolumn{2}{|l|}{ Collection of urine samples } & \multicolumn{2}{|l|}{$13(62)$} \\
\hline \multicolumn{2}{|c|}{ Clinical Laboratory Improvement Amendment-waived laboratories } & \multicolumn{2}{|l|}{$13(62)$} \\
\hline \multicolumn{2}{|l|}{ Licensed laboratory as part of practice } & \multicolumn{2}{|l|}{$5(24)$} \\
\hline Test result delivery method from external laboratories & Commercial Laboratory “A” & Commercial Laboratory "B" & Hospital \\
\hline Fax & $10(48 \%)$ & $8(38 \%)$ & $8(38 \%)$ \\
\hline Dedicated printer & $1(5 \%)$ & $1(5 \%)$ & $4(19 \%)$ \\
\hline Directly downloaded to electronic heath record & $10(48 \%)$ & $9(43 \%)$ & $8(38 \%)$ \\
\hline Other & $1(5 \%)$ & $1(5 \%)$ & $6(29 \%)$ \\
\hline
\end{tabular}


Table 3. Reported Method of Communicating Normal/ Clinically Insignificant Abnormal and Abnormal Laboratory Results to Patients, by Electronic Health Record (EHR)- versus Non-EHR-Enabled Practices*

\begin{tabular}{|c|c|c|}
\hline \multirow[b]{2}{*}{ Method of Communicating Results ${ }^{\dagger}$} & \multicolumn{2}{|c|}{$\begin{array}{l}\text { Practices That } \\
\text { Always/Often Use } \\
\text { Method, n }(\%)^{\ddagger}\end{array}$} \\
\hline & $\begin{array}{c}\text { Practices } \\
\text { With } \\
\text { EHR }\end{array}$ & $\begin{array}{c}\text { Practices } \\
\text { Without } \\
\text { EHR }\end{array}$ \\
\hline \multicolumn{3}{|l|}{$\begin{array}{l}\text { Normal and clinically insignificant } \\
\text { abnormal results }\end{array}$} \\
\hline Personal call from clinician & $104(41)$ & $36(32)$ \\
\hline $\begin{array}{l}\text { Medical assistant/nurse phone call } \\
\text { to patient }\end{array}$ & $137(54)$ & $36(32)$ \\
\hline Patient instructed to call & $54(22)$ & $25(23)$ \\
\hline $\begin{array}{l}\text { Patient to assume test is normal if } \\
\text { not notified }\end{array}$ & $68(27)$ & $30(28)$ \\
\hline Send personal note & $68(27)$ & $19(17)$ \\
\hline Send form letter to patient & $117(46)$ & $47(42)$ \\
\hline Mail copy of test results & $108(42)$ & $39(35)$ \\
\hline $\begin{array}{l}\text { Results available on secure } \\
\text { website for patients to access }\end{array}$ & $28(11)$ & $30(27)$ \\
\hline Results emailed to patients & $9(4)$ & $6(6)$ \\
\hline $\begin{array}{l}\text { Results available on automated } \\
\text { phone-in system }\end{array}$ & $2(<1)$ & $0(0)$ \\
\hline $\begin{array}{l}\text { Results available during patient } \\
\text { visit }\end{array}$ & $139(56)$ & $55(50)$ \\
\hline $\begin{array}{l}\text { Laboratory center directly notifies } \\
\text { patient }\end{array}$ & $5(2)$ & $0(0)$ \\
\hline \multicolumn{3}{|l|}{$\begin{array}{l}\text { Clinically significant abnormal } \\
\text { results }\end{array}$} \\
\hline Personal call from clinician & $204(81)$ & $83(75)$ \\
\hline $\begin{array}{l}\text { Medical assistant/nurse phone call } \\
\text { to patient }\end{array}$ & $136(54)$ & $33(30)$ \\
\hline Patient instructed to call & $48(20)$ & $19(18)$ \\
\hline Send personal note & $39(16)$ & $10(9)$ \\
\hline $\begin{array}{l}\text { Results available on secure } \\
\text { website for patients to access }\end{array}$ & $22(9)$ & $25(24)$ \\
\hline Results emailed to patients & $8(3)$ & $7(7)$ \\
\hline $\begin{array}{l}\text { Results available on automated } \\
\text { phone-in system }\end{array}$ & $5(2)$ & $0(0)$ \\
\hline Send form letter to patient & $55(23)$ & $26(24)$ \\
\hline Mail copy of test results & $71(29)$ & $31(29)$ \\
\hline $\begin{array}{l}\text { Results available during patient } \\
\text { visit }\end{array}$ & $110(46)$ & $50(46)$ \\
\hline $\begin{array}{l}\text { Laboratory center directly notifies } \\
\text { patient }\end{array}$ & $6(3)$ & $1(<1)$ \\
\hline
\end{tabular}

Bold indicates significant different between clinicians and staff and managers.

*Analysis was confined to responses from the 17 practices with an internal response rate of at least $70 \%$, by role.

${ }^{\dagger}$ Row percentage for each notification method could be $<100 \%$ because not every respondent selected each method.

${ }^{\ddagger}$ Respondents to the survey (clinicians, staff, and managers) were able to select all notification methods that apply to their practice; therefore, percentages may be $>100 \%$.
Table 4. Reported Method of Communicating Normal/ Clinically Insignificant Abnormal and Abnormal Laboratory Results to Patients, by Urban versus Rural Practice Location*

\begin{tabular}{|c|c|c|}
\hline \multirow[b]{2}{*}{ Method of Communicating Results ${ }^{\dagger}$} & \multicolumn{2}{|c|}{$\begin{array}{l}\text { Practices That } \\
\text { Always/Often Use } \\
\text { Method, n }(\%)^{\ddagger}\end{array}$} \\
\hline & Urban & Rural \\
\hline \multicolumn{3}{|l|}{$\begin{array}{l}\text { Normal and clinically insignificant } \\
\text { abnormal results }\end{array}$} \\
\hline Personal call from clinician & $127(40)$ & $22(31)$ \\
\hline $\begin{array}{l}\text { Medical assistant/nurse phone call to } \\
\text { patient }\end{array}$ & $125(40$ & $56(80)$ \\
\hline Patient instructed to call & $62(20)$ & $19(27)$ \\
\hline $\begin{array}{l}\text { Patient to assume test is normal if not } \\
\text { notified }\end{array}$ & $94(30)$ & $11(17)$ \\
\hline Send personal note & $72(23)$ & $17(24)$ \\
\hline Send form letter to patient & $145(46)$ & $30(43)$ \\
\hline Mail copy of test results & $138(44)$ & $15(21)$ \\
\hline $\begin{array}{l}\text { Results available on secure website for } \\
\text { patients to access }\end{array}$ & $58(19)$ & $1(1)$ \\
\hline Results emailed to patients & $15(5)$ & $0(0)$ \\
\hline $\begin{array}{l}\text { Results available on automated } \\
\text { phone-in system }\end{array}$ & $2(<1)$ & $0(0)$ \\
\hline Results available during patient visit & $153(50)$ & $53(75)$ \\
\hline $\begin{array}{l}\text { Laboratory center directly notifies } \\
\text { patient }\end{array}$ & $4(1)$ & $1(1)$ \\
\hline \multicolumn{3}{|l|}{ Clinically significant abnormal results } \\
\hline Personal call from clinician & $257(82)$ & $47(67)$ \\
\hline $\begin{array}{l}\text { Medical assistant/nurse phone call to } \\
\text { patient }\end{array}$ & $124(40)$ & $53(76)$ \\
\hline Patient instructed to call & $49(17)$ & $19(28)$ \\
\hline Send personal note & $43(14)$ & $9(13)$ \\
\hline $\begin{array}{l}\text { Results available on secure website for } \\
\text { patients to access }\end{array}$ & $47(16)$ & $1(1)$ \\
\hline Results emailed to patients & $15(5)$ & $0(0)$ \\
\hline $\begin{array}{l}\text { Results available on automated } \\
\text { phone-in system }\end{array}$ & $5(1)$ & $0(0)$ \\
\hline Send form letter to patient & $65(22)$ & $20(29)$ \\
\hline Mail copy of test results & $93(31)$ & $11(16)$ \\
\hline Results available during patient visit & $124(42)$ & $45(64)$ \\
\hline $\begin{array}{l}\text { Laboratory center directly notifies } \\
\text { patient }\end{array}$ & $5(2)$ & $2(3)$ \\
\hline
\end{tabular}

Bold indicates significant different between clinicians and staff and managers.

*Analysis was confined to responses from the 17 practices with an internal response rate of at least $70 \%$, by role.

${ }^{\dagger}$ Row percentages for each notification method could be $<100 \%$ because not every respondent selected each method.

${ }^{\ddagger}$ Respondents to the survey (clinicians, staff, and managers) were able to select all notification methods that apply to their practice; therefore, column percentages may be $>100 \%$.

\section{Patient Notification}

Table 5 summarizes the reported frequency across all surveyed practices for notifying patients about 
Table 5. Frequency With Which Practice Personnel Reported That the Practice Directly Notifies Patients of Laboratory Test Results $(\mathrm{n}=384)$

\begin{tabular}{lcc}
\hline & $\begin{array}{c}\text { Reported Patients Notified } \\
\text { Directly, n (\%) }\end{array}$ \\
\cline { 2 - 3 } Result & $\begin{array}{c}<96 \% \text { of the } \\
\text { Time }\end{array}$ & $\begin{array}{c}\text { Between } 96 \% \\
\text { to } 100 \% \text { of } \\
\text { the Time }\end{array}$ \\
\hline $\begin{array}{l}\text { Normal } \\
\text { Clinically insignificant abnormal } \\
\text { Clinically significant abnormal }\end{array}$ & $\begin{array}{c}255(66) \\
220(57)\end{array}$ & $129(34)$ \\
$105(27)$ & $279(73)$ \\
\hline
\end{tabular}

laboratory results that were normal, clinically insignificant abnormal (CIA), and clinically significant abnormal (CSA). Our results showed no significant differences in reported notification practices from EHR-enabled versus non-EHR-enabled practices, nor were urban results significantly different from those reported by rural practices. Nearly three quarters of clinicians (74\%) reported that the clinic directly notified patients of abnormal test results at least $96 \%$ of the time. Only two thirds of staff and managers $(63 \%)$ reported that the clinic directly notified patients of abnormal test results at least $96 \%$ of the time.

Tables 3 and 4 summarize the reported methods commonly used for communicating normal/CIA and CSA test results to patients and display for comparison the responses from EHR-enabled and non-EHR-enabled practices (Table 3) and urban and rural practices (Table 4). Importantly, approximately one quarter of practice personnel (for all surveyed practices combined) reported that their practice always or often informs patients that they should assume test results to be normal if they receive no notification from the practice. Respondents also generally agreed that the most common methods (always or often) of communicating normal/CIA laboratory results to patients were mailing a form letter or by mailing a photocopy of laboratory results; rural practices were less likely to mail copies of test results. Notification telephone calls from the clinician or staff also were reported to be frequently used (with much higher rates of staff rather than clinicians reported to be making the calls in rural practices), along with making the results available at the patient visit. Respondents reported a much higher use of telephone calls versus other methods to notify patients of CSA results, and rural practices reported a higher use of staff (medical assistants and nurses) to make these calls than did urban practices ( $76 \%$ vs $40 \%$ ).

We observed that approximately $20 \%$ of clinicians and $11 \%$ of staff rated their patient notification for normal or CIA results processes as "poor." About one third of staff also reported that patient notification systems were among their highest priorities for improvement (34\%). Qualitatively, respondents frequently described processes whereby laboratory test notifications often were triggered by patient calls and reported that patient calls for test results often were disruptive to practice workflows and that handling them was labor intensive.

\section{Tools and Reminders for Follow-Up Testing}

Respondents reported the use of EHR-based reminder systems, and their own internal "tickler" systems, as the most common mechanisms for assuring that required follow-up testing was ordered. Practices with at least a 25\% Medicaid and/or 20\% Medicare payer mix were more likely to have an EHR-based system rather than a stand-alone "tickler" file $(P=.01)$. In assessing practice responses to patient follow-up, $30 \%$ of clinicians and $17 \%$ of staff responded that they had no specific system. The most common response indicated that the EHR is flagged with follow-up recommendations. Staff and clinicians statistically differed in reporting who was responsible for documenting patient follow-up: $57 \%$ of staff, compared with $81 \%$ of clinicians, reported this to be the role of the clinician $(P<.001)$.

\section{Other Qualitative Themes}

In addition to the qualitative results reported above, respondents frequently reported human error and communication breakdown at the point of handoffs, as well as difficulty in sorting and handling results when returned from the laboratory. In addition, respondents reported concerns of "patient leakage" when referring to the phenomenon when patients sent to the laboratory draw station with the requisition forms do not show up, as well as having outdated or erroneous contact information to use when attempting to notify them patients about results.

\section{Discussion}

The aim of this study was to develop an understanding of the perceived gaps in laboratory testing 
processes-both internally and during handoffs between practices and laboratories-as reported by personnel in primary care practices. Data from these stakeholders provide useful insight into potential targets for process improvement activities. These survey results highlight the lack of standardized handoffs and definition of roles in ordering and monitoring tests and receiving and reporting results in primary care laboratory practices. The survey results also point to the high-priority gaps in processes that providers and staff identified as areas for practice improvement. As documented in the literature, the lack of standardization results in inefficient delivery of care, associated with higher costs, breakdowns in patient-centeredness, and medical errors. ${ }^{12}$ These failures result in laboratory test-related inefficiencies and lost revenue from patients who do not show up for a test or who file medical liability claims based on resulting failures. In their written responses, practices expressed a strong desire for more efficient and effective laboratory test processing systems. In addition, many respondents reported several inefficiencies with their current system(s).

The field of laboratory medicine traditionally allocated test ownership based on domain of workflow, with handoffs of ownership occurring at the preanalytic and analytic (ambulatory practice to laboratory) and the analytic and postanalytic (laboratory to ambulatory practice) phases of testing. The handoff challenges identified by primary care practice personnel highlight flaws in this silo domain model, and optimal solutions should be designed jointly by both parties. As an example of a joint approach, the College of American Pathologists recently released 4 different practice pathway examples for pathologists to demonstrate their value to accountable care organizations. ${ }^{13}$ One of the pathways they describe, called the patient diagnostic services center, is designed to combine laboratory medicine and diagnostic radiology services as partners in the ambulatory care setting. This partnership would allow for up-front, patient-centered diagnostic studies to improve the efficiency and productivity of subsequent ambulatory care visits. Our survey data support components of this type of ambulatory care and laboratory medicine partnership. Many believe that improving health care quality is linked to improving teamwork, especially at points of handoff, and laboratories have the potential to play a major role in developing handoff best practices.

The first handoff (practice to laboratory) immediately leaves many practices blind as to whether a test specimen was actually collected because the responsibility for action to enable collection is placed on the patient. Although not all primary care practices collect patient specimens, these practices still require reliable systems to track test status when patients go elsewhere to undergo laboratory testing. While practices may attempt to use their EHR CPOE, many resort to hand-written log books because of frustration with poorly functioning automated tools. Of even greater concern is that a number of practices reported that they have no system at all to track laboratory tests. Many laboratories receive test orders in CPOE environments, but these laboratories generally do not inform practices if the patient fails to arrive at a specimen collection center and the test is never received. EHR-based CPOE systems could be better used to flag potential errors of this type.

For the second handoff (laboratory to primary care), laboratories generally return test results to the ordering clinician. However, practices are complex environments, and the reconciliation of tests ordered and resulted generally does not fall to the ordering clinician. In fact, the survey data indicated that practice personnel recommended that someone other than the physician should perform test reconciliation. Laboratory tools that direct test results to personnel with a central practice function would improve practice efficiency and likely reduce errors secondary to missed test results.

These survey data also show that primary care practices use a variety of methods and different personnel for patient notification services. Some practices have a policy of not notifying patients of normal laboratory test results. This lack of patientcenteredness has multiple causes, one of which is the large number of practice-patient communications that this would entail. Some laboratories have created Internet-based portals that allow patients to view these test results, although laboratories could work even further to partner with ambulatory care practices in the result notification process.

For some testing activities, including patient notification, ambulatory care practice personnel showed levels of role confusion that may further contribute to practice inefficiencies and gaps in handoffs. These findings emphasize the benefit that 
laboratories could provide by assisting practices in standardizing work processes and personnel activities in the handoff steps.

A limitation of this study is that we measured only personnel responses from a set of practices in Colorado; geographic, economic, and other factors may affect personnel responses regarding handoff perceptions. We also did not evaluate practice perceptions of test selection and aspects of test result management practices (apart from patient notification). These phases of the total testing process affect testing handoffs, and improved practice-laboratory communication could positively affect these phases as well.

\section{Conclusion}

Gathering the perceptions of practice personnel are only a first step in substantially improving processes. We see the engagement of practices and their laboratory partners in process improvement activities, with the use of appropriate metrics with which to track progress, as the next logical step of this research.

\section{References}

1. Institute of Medicine. Crossing the quality chasm: a new health system for the 21 st century. Washington, DC: National Academies Press; 2001.

2. Joint Commission Perspectives on Patient Safety. Strategies to improve hand-off communication: implementing a process to resolve questions. Oak Brook (IL): Joint Commission; 2005. Available from: https://ps. mcic.com/appdocs/lps/Strategies\%20to\%20Improve\% 20Handoff $\% 20$ Communication.pdf. Accessed September 21, 2014.

3. Elder NC, Hickner J, Graham D. Quality and safety in outpatient laboratory testing. Clin Lab Med 2008; 28:295-303, vii.
4. Smith ML, Raab SS, Fernald DH, et al. Evaluating the connections between primary care practice and clinical laboratory testing: a review of the literature and call for laboratory involvement in the solutions. Arch Pathol Lab Med 2013;137:120-5.

5. Hickner J, Graham DG, Elder NC, et al. Testing process errors and their harms and consequences reported from family medicine practices: a study of the American Academy of Family Physicians National Research Network. Qual Saf Health Care 2008;17:194-200.

6. Fernald DH, Pace WD, Harris DM, West DR, Main DS, Westfall JM. Event reporting to a primary care patient safety reporting system: a report from the ASIPS Collaborative. Ann Fam Med 2004;2: 327-32.

7. Makeham MA, Dovey SM, County M, Kidd MR. An international taxonomy for errors in general practice: a pilot study. Med J Aust 2002;177:68-72.

8. Dovey SM, Meyers DS, Phillips RL Jr, et al. A preliminary taxonomy of medical errors in family practice. Qual Saf Health Care 2002;11:233-8.

9. Gandhi TK, Kachalia A, Thomas EJ, et al. Missed and delayed diagnoses in the ambulatory setting: a study of closed malpractice claims. Ann Intern Med 2006;145:488-96.

10. Dillman DA. The design and administration of mail surveys. Annu Rev Sociol 1991;17:225-49.

11. Miles MB, Huberman AM. Qualitative data analysis: an expanded sourcebook. Thousand Oaks (CA): SAGE Publications; 1994.

12. Christenson RH, Snyder SR, Shaw CS, et al. Laboratory medicine best practices: systematic evidence review and evaluation methods for quality improvement. Clin Chem 2011;57:816-825.

13. Promising practice pathways. Northfield (IL): College of American Pathologists; 2012. Available from: http://www. cap.org/apps/docs/reference/promising-pathways_ full_new.pdf. Accessed August 9, 2013. 